\title{
Pemanfaatan Sistem iMe Berbasis WordPress sebagai Official Site RCEP pada Perguruan Tinggi
}

\section{The Use of iMe System WordPress Based as Official Site RCEP on College}

\author{
Untung Rahardja*1, Indri Handayani ${ }^{2}$, Anggun Aditya Ningrum ${ }^{3}$ \\ 1,2,3 Sistem Informasi STMIK Raharja \\ E-mail: *11 Untung@raharia.info, ${ }^{2}$ Indri@raharja.info, ${ }^{3}$ Anggun@raharja.info
}

\begin{abstract}
Abstrak
WordPress merupakan aplikasi sistem terbuka yang dibangun menggunakan bahasa pemrograman PHP dan basis data MySQL yang dimana keduanya merupakan bagian dari perangkat lunak sistem terbuka. Dengan perkembangan teknologi informasi yang sedemikian canggih, Official Site RCEP dikembangkan dalam upaya mengoptimalkan sistem registrasi dan mendukung kegiatan TOEFL pada Perguruan Tinggi. Pemanfaatan sistem iMe (iLearning Media) berbasis WordPress ini diharapkan mampu membuat implementasi pada Official Site RCEP dapat berjalan dengan efektif dan efisien, dengan terintegrasi pada RinfoApps yang merupakan media cloud computing, salah satunya adalah penggunaan RinfoForm yang dapat digunakan sebagai media Registrasi TOEFL Online yang ada pada Official Site RCEP. Tahapan implementasi penelitian ini menggunakan metode observasi, wawancara kepada ketua pelaksana RCEP, serta metode studi pustaka. Selain sebagai media Registrasi TOEFL Online, Official Site RCEP juga digunakan sebagai wadah yang dapat memberikan informasi-informasi yang berkaitan dengan pelaksanaan TOEFL secara online pada Perguruan Tinggi Raharja. Dengan adanya Official Site RCEP ini diharapkan mampu mengatasi berbagai persoalan yang sering dihadapi dari registrasi TOEFL yang berjalan secara manual seperti hilangnya data, rusaknya data pendaftar, dan ketidakefisienan waktu.
\end{abstract}

Kata Kunci - iLearning Media, Registrasi, RCEP, TOEFL, RinfoForm.

\begin{abstract}
WordPress is an open system application built using PHP programming languages and MySQL database where both are part of open system software. With such a sophisticated development of information technology, the Official Site RCEP is developed in an effort to optimize the registration system and support the TOEFL activity in Higher Education. The use of iMe (iLearning Media) system based on WordPress is expected to make the implementation on Official Site RCEP can run effectively and efficiently, integrated with RinfoApps which is a cloud computing media, one of which is the use of RinfoForm which can be used as an Online TOEFL Register medium on the Official Site of RCEP. Stages of implementation of this study using the method of observation, interviews to the chief executive of RCEP, as well as literature study method. In addition to being a medium of Online TOEFL Registration, Official Site RCEP is also used as a container that can provide information related to the implementation of TOEFL online at Raharja Higher Education. With the Official Site RCEP is expected to overcome many problems that often faced from registration that runs manually TOEFL such as loss of data, damaged data registrant, and inefficiency of time.
\end{abstract}

Keywords - iLearning Media, Registrasi, RCEP, TOEFL, RinfoForm. 


\section{PENDAHULUAN}

Peningkatan kebutuhan teknologi dan informasi yang sangat signifikan dalam masyarakat dari berbagai bidang kian menuntut kita untuk terus melahirkan maupun melakukan pengembangan bagi sistem yang telah ada. Kemajuan akan kebutuhan teknologi informasi dipengaruhi oleh semakin mudahnya seseorang untuk dapat mengakses informasi apa saja dimana saja dan kapan saja hanya dengan bermodalkan internet. Menurut hasil data statistik APJII (Asosiasi Penyelenggara Jasa Internet Indonesia) Jumlah pengguna internet di Indonesia pada tahun 2016 sebanyak 137,2 juta user dengan didominasi oleh usia muda atau dapat dikatakan usia produktif [1].

Kemajuan Teknologi Informasi sangat berpengaruh dan memberikan manfaat yang luar biasa bagi bidang pendidikan, Seperti yang telah kita ketahui sebelumnya bahwa teknologi informasi memiliki peranan yang penting dan sangat mempengaruhi sistem pendidikan yang berjalan. Memenuhi kebutuhan masyarakat akan informasi yang cepat, tepat, dan akurat merupakan tantangan tersendiri bagi suatu instansi pendidikan baik formal maupun non formal. Perguruan Tinggi Raharja merupakan salah satu instansi pendidikan yang memiliki konsentrasi dalam bidang teknologi informasi dan komputer, untuk itu Perguruan Tinggi Raharja senantiasa terus berinovasi dalam menciptakan program ataupun sistem-sistem yang dapat digunakan untuk mendukung kegiatan perkuliahan.

WordPress merupakan salah satu CMS (Content Management System) yang paling banyak digunakan [2]. WordPress menggunakan bahasa pemrograman PHP dan Basis data (Database) MySQL yang dimana keduanya merupakan bagian dari perangkat lunak sistem terbuka (Open Source Software)

iLearning Media (iMe) merupakan sebuah official portal blogging yang dipersembahkan khusus untuk Pribadi Raharja, dan setiap pribadi raharja akan mendapatkan sub domain sebagai media dokumentasi segala bentuk aktivitas tridharma. iLearning Media di Perguruan Tinggi Raharja adalah sebuah aplikasi website sebagai media penyimpanan dan penyampaian tugastugas mahasiswa kepada dosen pengajar yang mengadopsi WordPress sebagai medianya [3]. Official Site RCEP memanfaatkan iLearning Media (iMe) yang dimana iMe ini mengadopsi WordPress sebagai aplikasi sistem terbuka (Open Source).

Saat ini proses registrasi TOEFL yang berjalan pada Perguruan Tinggi Raharja masih berjalan dengan manual yaitu dengan menggunakan kertas yang dapat hilang dan rusak serta menyebabkan penumpukan berkas. Jika dilihat dari sudut pandang sistem, saat ini Perguruan Tinggi Raharja telah memiliki sebuah Official Site RCEP yang dapat dijadikan sebagai wadah untuk mendukung proses registrasi TOEFL agar dapat berjalan secara online, juga untuk memberikan informasi-informasi yang berkaitan dengan kegiatan TOEFL seperti rekapan score dari pelaksanaan test TOEFL.

\section{METODE PENELITIAN}

Dalam proses penulisan karya ilmiah ini dibutuhkan adanya metode penelitian yang berguna untuk mencapai tujuan dan guna untuk mendapatkan informasi akurat yang dibutuhkan oleh penulis untuk melakukan beberapa tahapan dalam penelitian ini. Dalam penelitian ini penulis menggunakan beberapa metode penelitian diantaranya metode pengumpulan data yang terdiri dari observasi, wawancara, serta metode studi pustaka. 


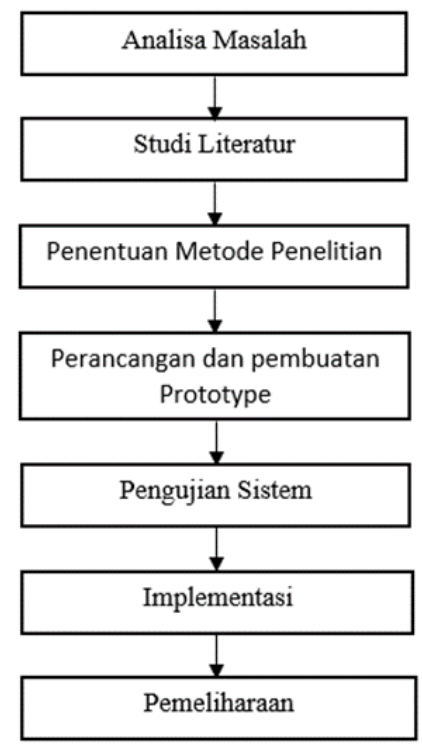

Gambar 1. Tahapan Penelitian

Berdasarkan Gambar 1 di atas berisi keterangan sebagai berikut:

1. Analisa Masalah, melakukan Analisa mengenai permasalahan yang dihadapi dari sistem yang sedang berjalan.

2. Studi Literatur, yaitu dengan mencari, membaca, dan memahami berbagai sumber referensi penelitian sejenis yang berasal dari buku dan jurnal-jurnal sebelumnya yang dapat dijadikan acuan dalam penelitian.

3. Penentuan Metode Penelitian, menentukan metode-metode penelitian apa saja yang paling relevan dengan penelitian yang sedang dilakukan, dengan memilih metode penelitian menggunakan Google Form atau Rinfo Form guna membuat program registrasi TOEFL secara online.

4. Perancangan dan Pembuatan Prototype, setelah membuat konsep rancangan dan metode penelitian langkah selanjutnya adalah membuat prototype program agar Perancangan dapat lebih mudah dipahami.

5. Pengujian Sistem, melakukan pengujian sistem yang dengan tujuan untuk menampilkan keunggulan dari sistem lama dan mengurangi kesalahan yang ditimbulkan dari sistem yang baru dan bertujuan untuk mengevaluasi apakah sistem sudah sesuai dengan harapan user.

6. Implementasi, apabila sistem telah sesuai dengan yang diharapkan user maka langkah selanjutnya adalah proses implementasi agar sistem dapat benar-benar digunakan dan direalisasikan dengan baik.

7. Pemeliharaan, Tahapan terakhir adalah memelihara dan menjaga agar sistem yang telah diimplementasikan dapat terawat dengan baik.

\subsection{Metode Pengumpulan Data}

\subsection{1. $\quad$ Metode Observasi}

Metode observasi adalah teknik atau metode pengumpulan data dengan melakukan pengamatan secara langsung di lokasi yang menjadi tempat penelitian, dalam penelitian ini penulis melakukan pengamatan langsung di Perguruan Tinggi Raharja. 


\subsubsection{Metode Wawancara}

Metode wawancara merupakan metode yang dilakukan kepada narasumber dengan cara mengajukan pertanyaan-pertanyaan yang mendukung permasalahan [4]. Dalam penelitian ini penulis melakukan wawancara secara langsung kepada ketua pelaksana RCEP dan mendapatkan gambaran permasalahan yang ada pada proses registrasi TOEFL yang berjalan saat ini pada Perguruan Tinggi Raharja.

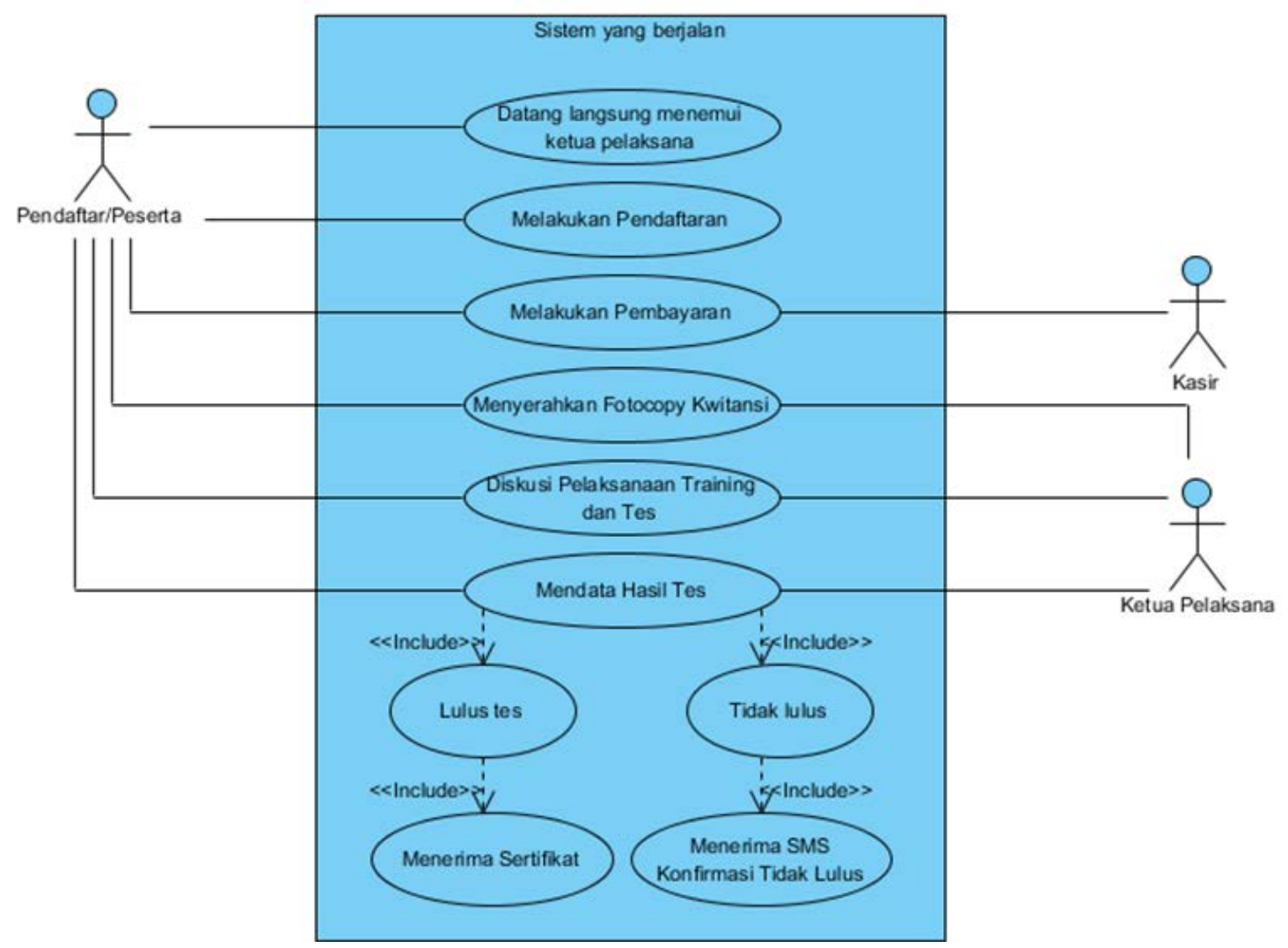

Gambar 2. Use Case Diagram pada Sistem Yang Berjalan

Berdasarkan uraian pada Gambar 2 use case diagram tersebut dapat disimpulkan bahwa belum adanya sebuah sistem yang digunakan sebagai penunjang untuk proses registrasi toefl, sehingga prosesnya saat ini masih berjalan secara manual serta banyak memakan waktu dan biaya. Karena bagi calon pendaftar harus datang terlebih dahulu ke Perguruan Tinggi Raharja untuk melakukan pendaftaran dan pembayaran.

\subsubsection{Studi Pustaka}

Metode studi pustaka merupakan metode yang dilakukan dengan mengumpulkan berbagai informasi yang didapatkan dari buku-buku, literatur-literatur, dan penelitian serta karya ilmiah sebelumnya. Berikut ini adalah beberapa penelitian-penelitian sebelumnya yang berkaitan dan memiliki kesamaan dengan penelitian yang sedang penulis bahas:

1. Penelitian yang dilakukan oleh Kartika Firdausy dan Muhammad Artha mengenai Paperless Office Berbasis WordPress [5]. Penelitian ini membahas tentang perlu dilakukannya upaya untuk mengurangi limbah kertas yang dihasilkan oleh perkantoran. Dalam hal ini, peneliti menerapkan sistem pengelolaan elektronik berbasis WordPress yang menyediakan sarana pengelolaan dokumen dalam format digital, sehingga diharapkan dapat mengurangi penggunaan kertas. 
2. Penelitian yang dilakukan oleh Indri Handayani, Herrafika Kusumahati, dan Alpiah Nurul Badriah mengenai Pemanfaatan Google Spreadsheet Sebagai Media Pembuatan Dashboard [2]. Dalam penelitian tersebut penulis membahas mengenai CCIT journal yang masih bersifat tradisional, sehingga penulis harus datang ke Perguruan Tinggi Raharja dan menyerahkan hasil penulisannya baik softcopy maupun hardcopy kepada admin sehingga memakan banyak waktu dan tenaga. Karena itu, diperlukan adanya sistem E-Journal dengan memanfaatkan iMe (iLearning Media) dan Rinfo (Raharja.Info) agar sistem penerimaan jurnal dapat berjalan dengan efektif dan efisien.

3. Penelitian yang dilakukan oleh Anjar Priyadna, dan Lies Yulianto mengenai Sistem Registrasi Kamar Hotel Berbasis Website [6]. Sistem yang sedang berjalan saat ini masih manual sehingga para calon tamu yang ingin mendaftar dan memesan kamar hotel harus datang langsung terlebih dahulu atau melalui media telepon, yang menyebabkan munculnya berbagai permasalahan diantaranya kekecewaan pengunjung yang ingin memesan tetapi seluruh kamar hotel sudah terisi oleh tamu. Untuk mengatasi masalah tersebut dibuatlah sistem yang dapat berguna bagi pengunjung yang ingin memesan dan melakukan registrasi secara online melalui website tersebut, juga sebagai media promosi dan registrasi calon tamu yang akan menggunakan jasa hotel.

4. Penelitian yang dilakukan oleh Ferrianto Gozali dan Billion Lo mengenai Pemanfaatan Teknologi Open Source Dalam Pengembangan Proses Belajar Jarak Jauh di Perguruan Tinggi [7]. Proses belajar mengajar yang bersifat konvensional, dimana dosen dan mahasiswa melakukan kegiatan tatap muka di ruang kelas seringkali mengalami berbagai kendala khususnya dalam waktu dan tempat. Untuk mengatasi kendala tersebut maka dikembangkan proses belajar jarak jauh dengan memanfaatkan TIK (Teknologi Informasi dan Komputer) dalam bentuk e-learning. Pengembangan e-learning ini menggunakan berbagai aplikasi yang bersifat open source.

5. Penelitian yang dilakukan oleh Hendri mengenai pemanfaatan CMS (Content Management System) sebagai solusi online marketing [8]. Sebagian besar UKM yang ada di Kota Jambi masih banyak yang belum memanfaatkan teknologi internet dalam mempromosikan hasil usahanya sehingga memungkinkan usahanya dapat dikenal oleh masyarakat luas baik dari dalam kota maupun luar kota Jambi. Pemasaran produk melalui dunia internet yang lebih dikenal dengan e-marketing ini tidak dilupakan begitu saja oleh para pelaku bisnis UKM. Salah satu cara memasarkan produk dengan e-marketing adalah dengan menggunakan Content Management System dan dilengkapi dengan pengujian melalui black box testing dan penggunaan kuesioner usability test.

6. Penelitian yang dilakukan oleh Eli Pujiastuti dengan judul Perancangan Sistem Informasi Pendaftaran Mahasiswa Aktif Kembali di STMIK Amikom Yogyakarta [9]. Perguruan Tinggi seperti STMIK Amikom Yogyakarta telah mengembangkan sistem dan infrastruktur untuk mendukung proses akademik, proses pemberian NIM mahasiswa baru yang melakukan pendaftaran masih dilakukan secara manual menggunakan Microsoft Xxcel dan Microsoft Word besarnya kemungkinan kesalahan, lamanya waktu tunggu pada sistem manual menjadi masalah yang mendasari peneliti membuat sebuah Perancangan sistem informasi pendaftaran mahasiswa aktif kembali di STMIK AMIKOM Yogyakarta. Hasil dari penelitian ini adalah dokumen untuk pengembangan sistem berikutnya, yang sebelumnya mengatur rumus secara manual menggunakan Microsoft Excel kini otomatis dihitung oleh sistem dan Sistem Informasi.

7. Penelitian yang dilakukan oleh Haissam Hajjar dan Abdelsalam Hajjar dengan judul Registrasi Online dan manajemen Berbasis Web [10]. Institute of Technology adalah institusi pendidikan yang memberikan Lisensi Diploma dengan prinsip LMD, siswa baru diterima dengan program baru sementara siswa yang ada akan terus mengikuti program lama. Artikel ini menjelaskan mengenai perangkat lunak yang dikembangkan untuk pengelolaan pendaftaran akademik termasuk penerapan kurikulum baru, kurikulum lama, dan transit antara kedua kurikulum tersebut. 


\section{HASIL DAN PEMBAHASAN}

\subsection{Analisa Permasalahan}

Perguruan Tinggi Raharja merupakan salah satu Perguruan Tinggi yang bergerak dalam bidang teknologi informasi dan komputer. Saat ini Perguruan Tinggi Raharja telah memiliki banyak sistem yang diperuntukkan khusus dalam menunjang perkuliahan agar dapat berjalan dengan efektif dan efisien. Salah satunya adalah sistem Official Site RCEP yang dirancang khusus untuk mendukung kegiatan TOEFL (Test of English as a Foreign Language). Namun, pemanfaatan dari official site RCEP dirasakan kurang optimal karena proses registrasi TOEFL yang berjalan saat ini masih dilakukan secara manual yang dimana seharusnya sudah dapat dilakukan secara online dengan memanfaatkan Official Site RCEP dan RinfoForm sebagai medianya. Proses registrasi TOEFL secara manual banyak menimbulkan masalah, diantaranya yaitu hilangnya data pendaftar, rusaknya data, serta tidak terdokumentasi dengan baik mengenai seluruh data-data pendaftar dari tahun-tahun sebelumnya maupun tahun yang akan datang. Proses registrasi TOEFL yang berjalan secara manual juga banyak membuang waktu dan biaya, dimana seharusnya dapat diefisienkan dengan baik sehingga proses registrasi TOEFL dapat dilakukan dimana saja dan kapan saja tanpa perlu berada dalam lingkungan kampus Perguruan Tinggi Raharja.

Dalam penelitian sebelumnya tampilan Official Site RCEP masih sangat tidak informatif dan tidak official. Proses registrasi TOEFL pun masih dilakukan secara manual yang artinya registrasi TOEFL secara online belum terealisasikan dan tidak diimplementasikan dengan baik. Dalam penelitian sebelumnya juga tidak menyediakan sebuah wadah yang dapat digunakan untuk mengupload bukti pembayaran sehingga pendaftar masih harus memfotocopy terlebih dahulu bukti pembayaran registrasi TOEFLnya. Juga tidak adanya prosedur yang jelas yang diperuntukkan guna memudahkan bagi calon pendaftar yang ingin mendaftarkan dirinya menjadi peserta training dan tes TOEFL RCEP di Perguruan Tinggi Raharja. 
Citec Journal, Vol. 4, No. 3, Mei 2017 - Juli 2017

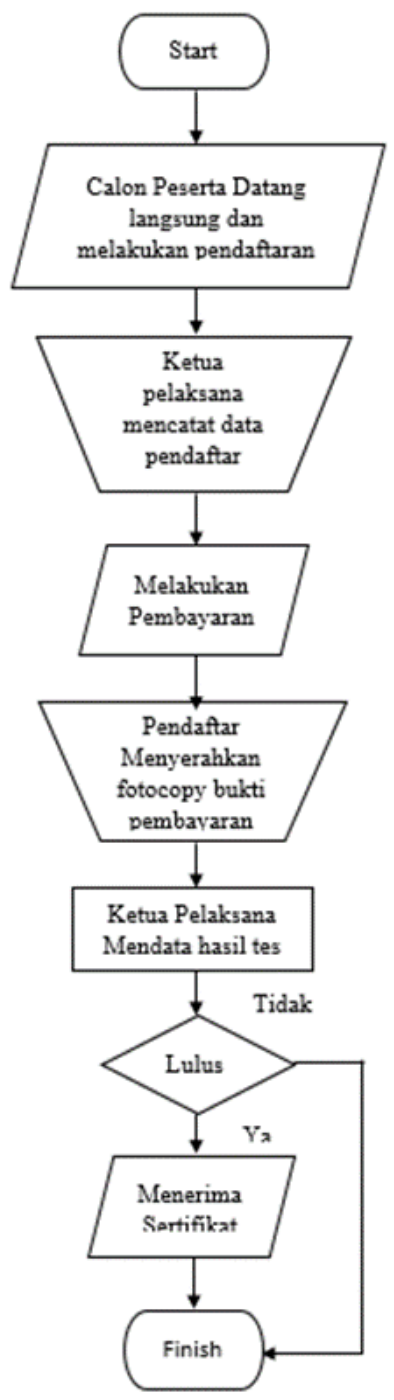

Gambar 3. Flowchart Sistem Berjalan Saat ini.

Gambar 3 merupakan flowchart sistem yang sedang berjalan saat ini, yang terdiri dari:

1. Dua simbol titik terminal yang dianalogikan sebagai symbol start dan finish pada sistem registrasi TOEFL yang berjalan secara manual.

2. Tiga simbol input/output yang menyatakan bahwa proses tersebut tidak bergantung pada jenis peralatannya.

3. Dua simbol operasi manual yang menyatakan bahwa proses pengolahan tidak dilakukan dengan komputer.

4. Satu simbol proses yang menunjukkan bahwa pengolahan yang dilakukan dengan komputer.

\subsection{Pemecahan Masalah}

Untuk memecahkan permasalahan yang ada pada proses registrasi TOEFL yang masih berjalan secara manual maka diperlukan adanya sebuah sistem registrasi TOEFL yang dapat dijalankan secara online dengan memuat berbagai informasi mengenai TOEFL secara informatif. 


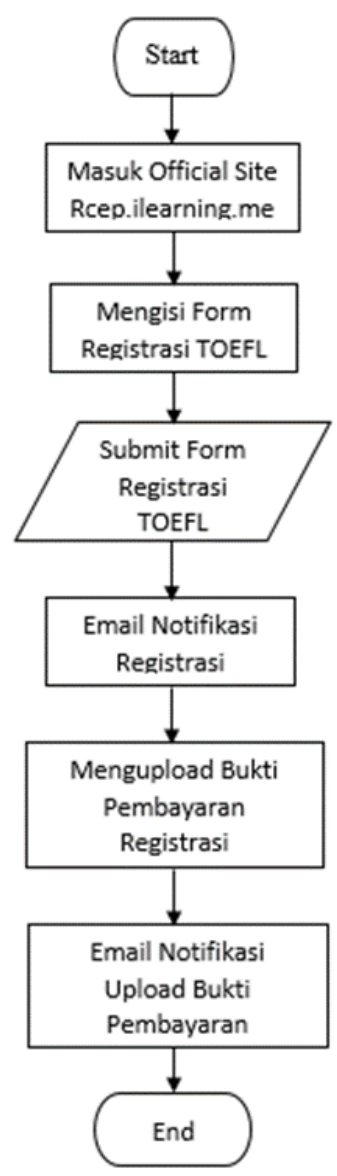

Gambar 4. Flowchart Sistem Yang Diusulkan

Pada Gambar 4, dapat dijelaskan pada Flowchart sistem registrasi TOEFL Online yang diusulkan diatas terdiri dari:

1. Duasimbol terminal yang berperan sebagai start dan end pada alur proses flowchart.

2. Lima simbol proses yang berperan sebagai tindakan proses yang dilakukan oleh komputer, simbol tersebut mengawali akses dalam official site rcep dan pada saat mengisi form registrasi TOEFL secara online.

3. Satu simbol input dan output data.

Official Site RCEP adalah sebuah sistem informasi yang menggunakan iMe (iLearning Media) sebagai wadah untuk menciptakan kemudahan dan memberikan kelancaran dalam proses registrasi TOEFL secara online (Test of English as a Foreign Language) bagi siapapun yang belum dan ingin memiliki sertifikat TOEFL dengan mengikuti training dan test. Official Site RCEP juga memudahkan bagi para peserta pelaksanaan training dan test TOEFL di Perguruan Tinggi Raharja untuk dapat mengakses dan melihat hasil scorenya dengan tepat, baik hasil score TOEFL pribadi maupun hasil score yang diperoleh orang lain. Official Site RCEP juga tidak hanya dapat diakses oleh Pribadi Raharja tetapi juga oleh khalayak umum, cukup dengan hanya mengunjungi halaman http://rcep.ilearning.me/ maka siapapun dapat dengan mudah melakukan registrasi dan mendapatkan informasi-informasi yang berkaitan dengan TOEFL dengan mudah dan akurat. Dengan diterapkannya Registrasi TOEFL secara online ini diharapkan mampu mengatasi berbagai persoalan dan masalah-masalah yang menyangkut dan berkaitan dengan proses registrasi TOEFL di Perguruan Tinggi Raharja. Proses registrasi TOEFL yang berjalan secara online juga mampu memudahkan siapa saja yang ingin mendaftarkan diri menjadi peserta training dan test TOEFL RCEP karena Form Registrasi TOEFL yang sangat mudah digunakan 
Citec Journal, Vol. 4, No. 3, Mei 2017 - Juli 2017

oleh siapa saja dan prosedur pendaftaran yang sangat fleksibel sehingga tidak sulit untuk dipahami bahkan oleh orang awam sekalipun.

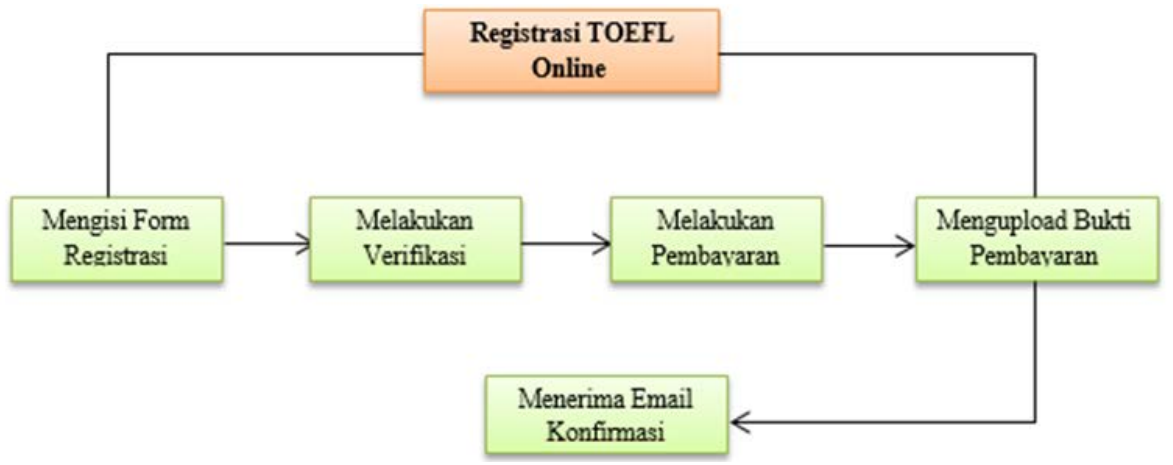

Gambar 5. Prosedur Registrasi TOEFL yang Diimplementasikan

Berdasarkan Gambar 5 di atas menunjukkan urutan-urutan yang menjelaskan bahwa, dengan adanya prosedur pendaftaran tersebut dapat dijadikan panduan bagi calon pendaftar yang ingin mendaftarkan diri menjadi peserta training dan test TOEFL RCEP.

1. Tampilan Homepage Official Site RCEP

HOME

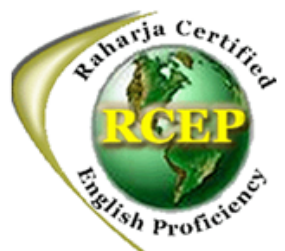

SELAMAT DATANG DI OFFICIAL SITE RCEP PERGURUAN TINGGI RAHARJA

"RCEP (Raharja Certified English Proficiency)" adalah paket jaminan mutu kemampuan berbahasa Ingsris Pribadi Raharja yang terdiri dari perkuliahan, training, ujian serta sertifikasi yang diselenggarakan pada lingkungan Perguruan Tinggi Raharja. RCEP juga merupakan The Preparation of the Test of English as a Foreign Language (TOEFL), tujuanya adalah untuk Meningkatkan kompetensi SDM dalam berbahasa Inggris.

\section{WHY TOEFL ???}

Mengapa sertifikat TOEFL sangat diperlukan ?

\section{SUBSCRIBE}

Please subscribe by filling your email here!

Email *

\section{Subscribe}

VISITOR

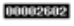

Ask question on iDuHelp!

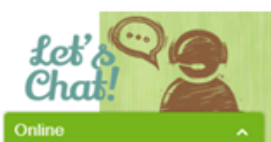

Gambar 6. Tampilan Homepage pada Official Site RCEP

Berdasarkan Gambar 6 di atas menampilkan website official site RCEP ini dapat diakses kapanpun dan dimanapun dengan memanfaatkan jaringan internet, cukup dengan mengakses melalui http://rcep.ilearning.me/ maka user dapat dengan mudah mendaftarkan diri menjadi peserta training dan test TOEFL RCEP di Perguruan Tinggi Raharja. Official Site RCEP memiliki tampilan yang sangat user friendly dan dilengkapi dengan icon-icon pendukung seperti terlihat pada Gambar 6. 
2. Tampilan Menu Form Registrasi TOEFL

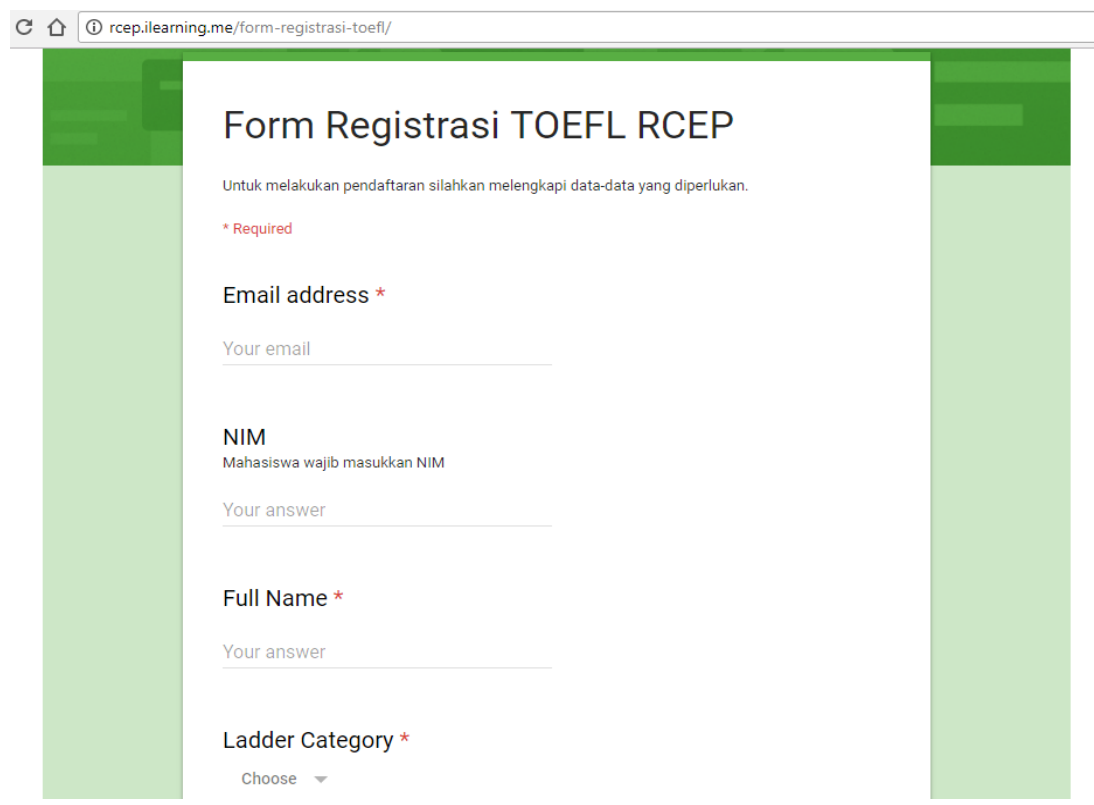

Gambar 7. Form Registrasi TOEFL

Pada Gambar 7, menjelaskan bahwa Form Registrasi ini dibuat menggunakan RinfoForm. Google Form atau yang biasa disebut Rinfo Form adalah salah satu aplikasi yang disediakan oleh Google pada Rinfo untuk membuat berbagai aplikasi Form. Pada pembuatan Form Registrasi TOEFL Online ini penulis juga melengkapi dengan FormEmailer agar ketika data pendaftar dapat tersimpan dengan baik dalam database. FormEmailer juga berguna untuk mengaktifkan notifikasi agar ketika ada pendaftar yang mengisi form tersebut maka secara otomatis admin akan mendapatkan email notifikasi.

\begin{tabular}{|c|c|c|}
\hline Email & \multicolumn{2}{|c|}{ Advanced } \\
\hline & Answer: & $v$ \\
\hline \multirow{2}{*}{$\begin{array}{r}\text { Sender Name: } \\
\text { Reply To }\end{array}$} & FormEmailer & \multirow{6}{*}{$\begin{array}{l}\text { - insert placeholder } \\
\text { - insert placeholder } \\
\text { - insert placeholder } \\
\text { - insert placeholder } \\
\text { - insert placeholder } \\
\text { - insert placeholder }\end{array}$} \\
\hline & toefl.rcep@raharja.info & \\
\hline To: & anggun@raharja. info & \\
\hline $\mathrm{Cc}$ & \#Email Address\# & \\
\hline$B c c$ & nurlaila@raharja.info & \\
\hline Subject: & New Form Submitted & \\
\hline $\begin{array}{l}\text { Body: } \\
\text { html }\end{array}$ & \multicolumn{2}{|l|}{ 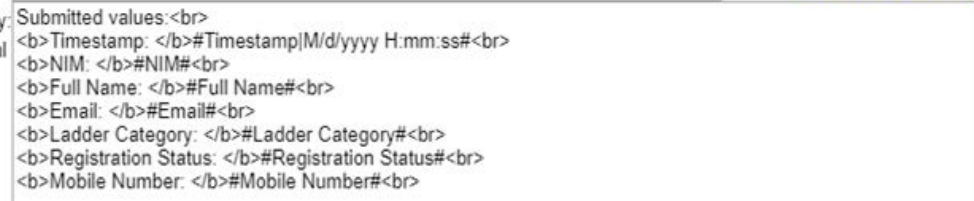 } \\
\hline \multicolumn{3}{|c|}{ Save and Close } \\
\hline
\end{tabular}

Berdasarkan Gambar 8 di atas, menampilkan FormEmailer yang berisikan mengenai Script Editor yang digunakan untuk mengatur notifikasi pada spreadsheets respon agar saat ada yang melakukan pendaftaran dengan mengisi Form Registrasi secara otomatis respon dapat terekam secara berurutan.

3. Tampilan Menu Upload Bukti Pembayaran 
Citec Journal, Vol. 4, No. 3, Mei 2017 - Juli 2017

(1) (1) rep.ilearning-me/upload-bukti-pembayaran

\section{UPLOAD BUKTI PEMBAYARAN}

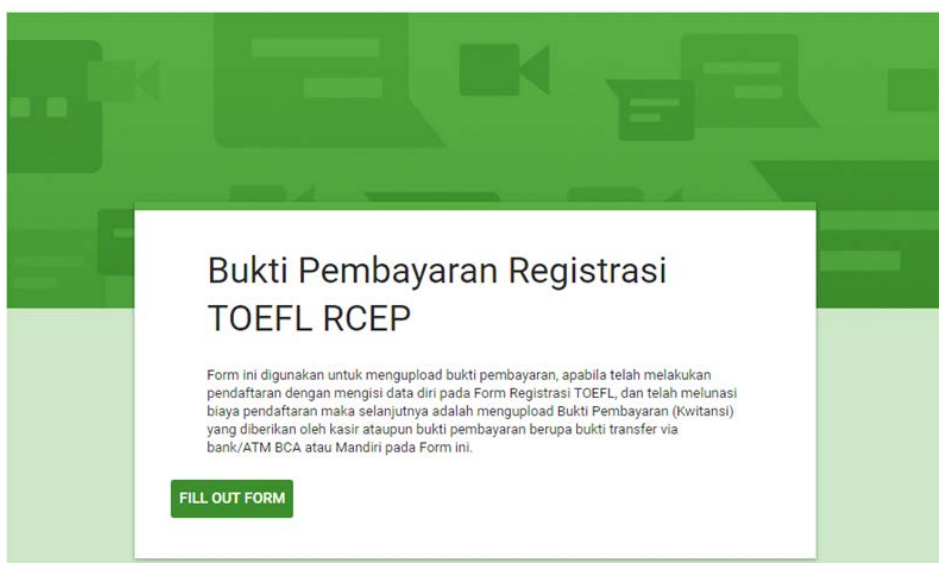

Gambar 9. Menu Bukti Pembayaran Registrasi TOEFL

Berdasarkan Gambar 9 di atas dapat dijelaskan bahwa, dengan adanya menu upload bukti pembayaran ini calon pendaftar menjadi lebih mudah jika akan melakukan pendaftaran, jadi tidak perlu datang ke Perguruan Tinggi Raharja hanya perlu mengisi Form Registrasi TOEFL lalu melakukan pembayaran dengan Transfer melalui No. Rekening Yayasan Nirwana Nusantara kemudian setelah itu melakukan Upload Bukti Pembayaran dengan mengupload bukti transfer via ATM/Bank BCA dan Mandiri, Jadi sangat efisien dari segi waktu dan biaya.

4. Tampilan Menu Rekap Score TOEFL

\section{4 (1) rcep.ilearning.me/2017/10/18/rcep-151/}

\section{RCEP 151}

By Anggun Aditya Ningrum in Uncategorized on October 18, 2017.

\begin{tabular}{|c|c|c|c|c|c|}
\hline NO. URUT & NIM & NO. SERTIFIKAT & NAMA & SCORE & GRADE \\
\hline 1 & 1633494196 & 3936 & Fajar Nur Iman & 553 & A \\
\hline 2 & 1633494094 & 3937 & Ade Muhamad Ridwan & 553 & A \\
\hline 3 & 1521489384 & 3938 & Alia Ghofar & 550 & A \\
\hline 4 & 1612494120 & 3939 & Helda Angesti & 547 & B \\
\hline 5 & 1611494543 & 3940 & Widya Febriana & 537 & B \\
\hline 6 & 1612495225 & 3941 & Fahmi Muhammad & 533 & B \\
\hline 7 & 1622395697 & 3942 & Siti Khodijah & 533 & B \\
\hline 8 & 1511489090 & 3943 & Dedy Kurniawan & 513 & B \\
\hline 9 & 1511489218 & 3944 & Rise Wijoyo Jati & 510 & B \\
\hline 10 & 1612494186 & 3945 & Abizal Al Farobie & 510 & B \\
\hline 11 & 1611493966 & 3946 & Dewi Nur Khasanah & 507 & B \\
\hline
\end{tabular}

Gambar 10. Contoh rekapan RCEP 151

Pada Gambar 10 di atas, menunjukkan bahwa dengan adanya menu Rekap Score TOEFL peserta yang sudah mengikuti test TOEFL dapat dengan mudah mengetahui hasil dari keseluruhan peserta dan tentunya hasil score TOEFL pribadi. Dengan menggunakan TablePress dapat memudahkan dalam pencarian nama. Jadi bukan hanya dapat melihat nilai pada 1 (satu) periode melainkan periode-periode sebelumnya juga dapat diakses dengan mudah. 
5. Tampilan Menu Contact Us

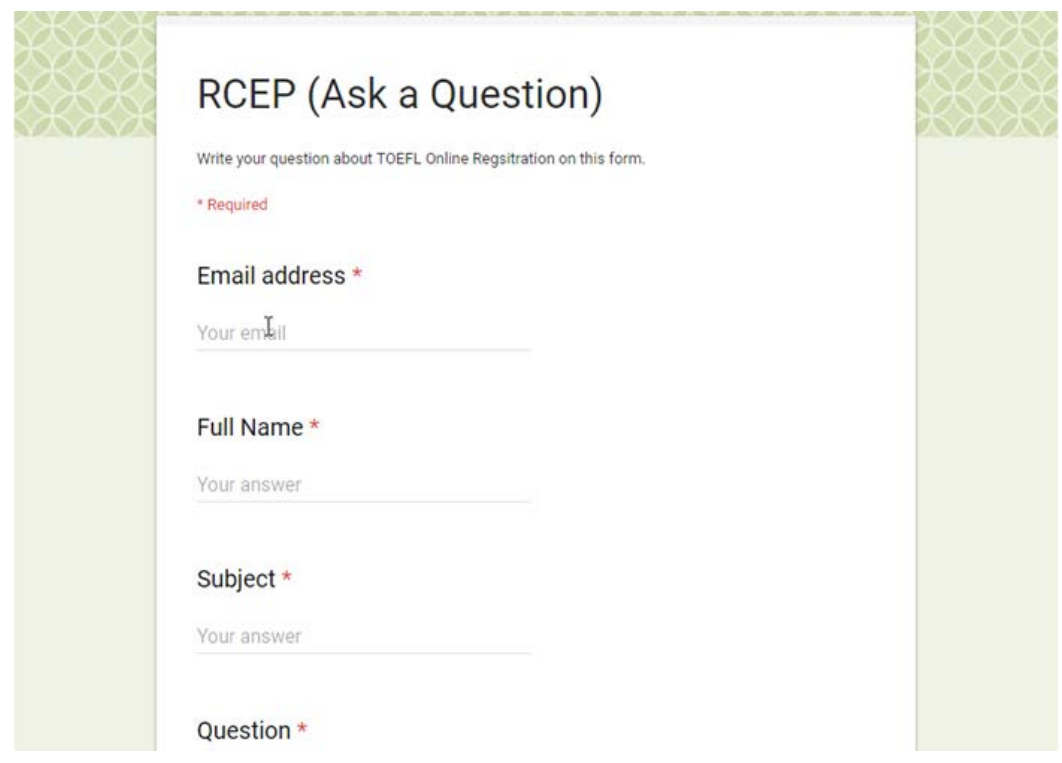

Gambar 11. Form Keluhan atau pertanyaan dalam Menu Contact US

Dalam Gambar 11 di atas menjelaskan bahwa menu Contact Us ini di lengkapi dengan Rinfo Maps dan Form, agar jika pendaftar mengalami kesulitan dan ingin bertanya perihal masalahnya saat akan melakukan pendaftaran bisa langsung mengisi form tersebut untuk kemudian langsung direspon oleh admin.

\section{KESIMPULAN}

Dapat disimpulkan bahwa pemanfaatan iMe (iLearning Media) Berbasis WordPress dalam Implementasi Official Site RCEP ini sangat memberikan kemudahan dan telah sesuai dengan kebutuhan dalam pelaksanaan registrasi TOEFL secara online. Dibandingkan dengan penelitian sebelumnya bahwa registrasi TOEFL masih dilakukan secara manual dan belum diimplementasikan secara online dengan baik.

Beberapa Informasi yang dimuat sebelumnya dalam Official Site RCEP:

1. Official Site RCEP hanya memuat mengenai Rekap Score TOEFL peserta yang telah lulus training dan tes TOEFL di Perguruan Tinggi Raharja.

2. Belum adanya proses ataupun sistem registrasi TOEFL secara online sehingga proses registrasi TOEFL masih dilakukan secara manual

3. Tidak adanya prosedur registrasi TOEFL yang dapat dengan mudah dipahami oleh calon pendaftar.

Maka dapat disimpulkan dengan adanya Official Site RCEP ini memiliki kelebihan diantaranya:

1. Official Site RCEP dapat memberikan informasi yang informatif mengenai pelaksanaan TOEFL di Perguruan Tinggi Raharja.

2. Official Site RCEP dapat dijadikan wadah official untuk proses registrasi TOEFL secara online yang dapat diakses dengan mudah dimana saja dan kapan saja.

3. Dengan penerapan Registrasi TOEFL secara online juga dapat meminimalisir rusak dan hilangnya data pendaftar.

4. Rekap score dari peserta yang telah lulus training dan tes pun dapat terdokumentasi dengan baik. 
5. Dengan adanya Viewboard atau yang biasa disebut dengan Dashboard dalam Official Site RCEP dapat memudahkan admin dan pengunjung situs untuk dapat dengan mudah mengetahui presentase pendaftar TOEFL RCEP setiap periode dan setiap bulannya.

\section{SARAN} adalah:

Saran yang ingin penulis sampaikan untuk dapat dikembangkan dalam penelitian ini

1. Perlu adanya perbaikan dan pembaruan sistem secara berkala agar sistem dapat menampilkan tampilan yang lebih baik dan lebih menarik.

2. Perlu adanya peningkatan dalam tampilan Form Registrasi TOEFL agar lebih official namun tetap User Friendly.

3. Diharapkan agar pihak pengembang selanjutnya dapat menambahkan fitur-fitur baru yang sekiranya dibutuhkan untuk dapat membuat sistem menjadi lebih informatif dan memiliki tampilan yang lebih menarik lagi.

\section{DAFTAR PUSTAKA}

[1] Isparmo, 2016, Data Statistik Pengguna Internet Indonesia Tahun 2016, http://isparmo.web.id/2016/11/21/data-statistik-pengguna-internet-indonesia-2016/, diakses tanggal 13 Februari 2018.

[2] Krisianto, A. 2014, Jago WordPress, Elex Media Komputindo, Jakarta.

[3] Handayani, I., Kusumahati, H., Badriah, A. N, 2017, Pemanfaatan Google Spreadsheet Sebagai Media Pembuatan Dashboard Pada Official Site iFacility di Perguruan Tinggi, Jurnal SISFOTENIKA, No. 2, Vol. 7, Hal. 177-186.

[4] Habibie, F. H., Purnama, B. E., dan Triyono, R. A., 2014, Pembangunan Sistem Informasi Penerimaan Calon Tenaga Kerja Secara Online Berbasis Web Pada Bursa Kerja Khusus Smk Ganesha Tama Boyolali, Jurnal Teknologi Informasi dan Komunikasi, No.2, Vol. 5, Hal. 7783

[5] Kartika, F., Artha, M., 2012, Perancangan dan Implementasi Paperless Office Berbasis WordPress di ITTC UAD, Jurnal Spektrum, No. 1, Vol. 10, Hal. 84-98.

[6] Anjar, P., Yulianto, L., 2013, Pembuatan Sistem Registrasi Kamar Hotel Berbasis Website Pada Hotel Graha Prima Pacitan, Jurnal IJNS, No. 2, Vol. 2, hal 8-14.

[7] Gozali, F., Lo, B., 2012, Pemanfaatan Teknologi Open Source Dalam Pengembangan Proses Belajar Jarak Jauh di Perguruan Tinggi, Jurnal Nasional Pendidikan Teknik Informatika, No.1, Vol.1, Hal 47-57

[8] Hendri, 2013, Pemanfaatan Content Management System (CMS) sebagai solusi Online Marketing Untuk UKM di Kota Jambi, Jurnal SISFO, No.1, Vol.7, hal 1-12.

[9] Pujastuti, E., 2016, Perancangan Sistem Informasi Pendaftaran Mahasiswa Aktif Kembali di STMIK Amikom Yogyakarta, Jurnal Dasi, No.2, Vol.17, Hal 31-37.

[10] Hajjar, H., Hajjar, A., 2016, Software for Academic Registration for IUT SAIDA: WebBased Online Academic Registration and Management, Computational Science and Computational Intelligence (CSCI), 2016 International Conference, Las Vegas, Desember 15-17. 